\title{
LIPOPROTEIN AUGMENTATION OF HUMAN CHORIONIC GONADOTROPIN AND PROLACTIN STIMULATED PROGESTERONE SYNTHESIS BY RAT LUTEAL CELLS
}

\author{
M. Menon, H. Peegel and K. M. J. Menon* \\ Endocrine Laboratory, Departments of Obstetrics and Gynecology, and Biological Chemistry, \\ The University of Michigan Medical School, Ann Arbor, MI 48109, U.S.A.
}

(Received 27 February 1984)

\begin{abstract}
Summary-A collagenase dispersed cell suspension from PMSG-hCG primed immature rats responded to exogenously added hCG, cholera enteroxin, prolactin, and 8-Bromocyclic-AMP with increase in progesterone production in a dose dependent manner, and this stimulation was augmented by the plasma lipoprotein fractions hHDL and hLDL. The responsiveness to low doses of prolactin was not apparent when lipoprotein fractions were not included in the assay mixture. When the incubation mixture contained either LDL or HDL, the stimulatory effect of prolactin on progesterone production was evident at 5 and $10 \mu \mathrm{g}$ prolactin $/ \mathrm{ml}$ of the incubation mixture. Progesterone production, both basal and hormone stimulated, was maximum on day 7 of pseudopregnancy. Although the extent of hCG and prolittin stimulation of progesterone production and its potentiation by lipoprotein fractions was observed to be higher on days 3 and 5 than that seen on day 7 , the net amount of progesterone produced was highest on day 7. The basal as well as hormone and lipoprotein stimulated progesterone production started to decline after day 7 , reaching a nadir on day 14 . These experiments show that prolactin is effective in stimulating progesterone production by rat luteal cells in vitro and that lipoprotein fractions, LDL and HDL further potentiate this response. This study further suggests that it is important to include LDL or $\mathrm{HDL}$ as a source of cholesterol for in vitro experiments in which the steroidogenic response of luteal cells to exogenous stimuli is tested.
\end{abstract}

\section{INTRODUCTION}

In the rat, prolactin has been identified as a luteotropic hormone, since administration of prolactin resulted in the prolongation of estrus and maintainance of deciduomata formation and pregnancy in intact and hypophysectomized rats [1-3]. Rothchild et al. [4-6] have reported that the function of corpora lutea is regulated in the latter half of pseudopregnancy by LH and prolactin. Luteotropic response has also been observed in vitro using perifused rat corpora lutea by a combination of $\mathrm{LH}$ and prolactin [7]. In spite of these reports, direct addition of prolactin to luteal cell incubations have not produced a striking effect on progesterone production under in vitro conditions. Previous studies have shown that progesterone production by collagenase dispersed cells from PMSG-hCG primed rat ovaries is augmented by various gonadotropin preparations, and this responsiveness was potentiated by the exogenously added plasma lipoprotein fractions, high density lipoprotein (HDL), and low density lipoprotein (LDL) [8-11]. Further evidence for the direct incorporation of the exogenously supplied cholesterol in LDL into progesterone has also been described [9]. Specific binding and degradation of ${ }^{125}$ I-labeled LDL and HDL by the corpus luteum tissue has been demonstrated using luteal cells maintained in short

*To whom correspondence should be addressed. term cultures [12]. We have examined the possibility that since luteal cell steroidogenesis proceeds optimally in the presence of the exogenously added plasma lipoprotein fraction, LDL or $\mathrm{HDL}$, the prolactin effect may be potentiated in the presence of lipoproteins under in vitro conditions.

The purpose of the present study was, therefore, to examine the ability of luteal cells to utilize exogenously supplied sterols during the life span of the rat corpus luteum and to determine the relative abilities of various stimulants of steroidogenesis on the utilization of lipoprotein delivered cholesterol for progesterone production.

\section{EXPERIMENTAL}

\section{Materials}

Purified human choriogonadotropin (CR119, 11500 , I.U./mg) was generously supplied by Dr R. Canfield, Columbia University, New York, through Population Research Branch, National Institutes of Child Health and Human Development, National Institutes of Health, Bethesda, MD. 8-BrCyclic-AMP was obtained from Sigma Chemical Co., St Louis, MO, and 1-Methyl-3-isobutylxanthine (MIX) was purchased from Aldrich Chemical Co., Milwaukee, WI. Collagenase (Type CLS) and deoxyribonuclease were supplied by Worthington Biochemical Corporation, Freehold, NJ. Medium 109 was a product of Grand Island Biological Co., Grand 
Island, NY. Other reagents used were of analytical reagent grade. Cholera toxin was a product of Schwartz/Mann, Orangeburg, NY. Prolactin (NIHP-S-12) was generously supplied by the Hormone Distribution Program, National Institutes of Arthritis, Metabolic and Digestive Disease.

\section{Animals}

Immature (21-24-day old) Sprague-Dawley female rats purchased from Spartan Research Animals, Inc. of Haslett, MI were used in the experiments. They were treated with 50 I.U. of pregnant mare's serum gonadotropin (Gesty, Organon, Oss, Holland), followed $56 \mathrm{~h}$ later by a single dose of $25 \mathrm{I}$.U. of hCG (Sigma Chemical Co.) on day 0 to obtain highly luteinized ovaries [13]. The ovaries were collected at different intervals of time after hCG injection as described under each experiment.

\section{Preparation of luteal cells}

The animals were killed by cervical dislocation; the ovaries were removed and freed of connective tissues, weighed, and placed in Medium 109 containing $0.1 \%$ bovine serum albumin. Collagenase dispersed cells were prepared as described previously from this laboratory [14,15] with slight modifications [9]. Briefly, the ovaries were cut into small pieces (approx $1 \mathrm{~mm}^{3}$ ) with scissors and transferred to a $50 \mathrm{ml}$ plastic beaker. The tissue was suspended at a concentration of $50 \mathrm{mg} / \mathrm{ml}$ of Medium 109 containing 500 I.U. $/ \mathrm{ml}$ collagenase and $4 \mu \mathrm{G} / \mathrm{ml}$ DNAase. The samples were incubated for $60 \mathrm{~min}$ at $37^{\circ} \mathrm{C}$ in an atmosphere of $\mathrm{O}_{2}: \mathrm{CO}_{2}(95: 5, \mathrm{v} / \mathrm{v})$. At 30 and $60 \mathrm{~min}$ of incubation, the cells were dissociated by flushing the tissue and medium $30-40$ times through a $1 \mathrm{ml}$ plastic syringe. At the end of the incubation the cell suspension was diluted with 2 vol of medium and centrifuged at $600 \mathrm{~g}$ for $3 \mathrm{~min}$. The sedimented cells were washed two times in Medium 109/0.1\% bovine serum albumin and then resuspended to a concentration of approx $2 \cdot 10^{7}$ cells $/ \mathrm{ml}$. The viability of the cells ranged between $80-90 \%$, as ascertained by the trypan blue exclusion test. DNA was determined according to the procedure of Burton [16].

\section{Incubation conditions for progesterone measurement}

Unless otherwise stated, aliquots of luteal cells (approx $2 \times 10^{6}$ cells in $0.1 \mathrm{ml}$ ) were transferred into $12 \times 75 \mathrm{~mm}$ tubes containing $0.3 \mathrm{ml}$ Medium $109 / 0.1 \%$ bovine serum albumin, and, where required, appropriate concentrations of hCG, lipoproteins, or other agents were also added. The incubations were carried out at $37^{\circ} \mathrm{C}$ in a Dubnoff metabolic shaking incubator for $3 \mathrm{~h}$ in the presence of $\mathrm{O}_{2}: \mathrm{CO}_{2}(95: 5, \mathrm{v} / \mathrm{v})$. Following incubation, the reaction was stopped by placing the sample tubes in a boiling water bath for $3 \mathrm{~min}$. The samples were then diluted with $0.6 \mathrm{ml} \mathrm{H}_{2} \mathrm{O}$ and $10,000 \mathrm{cpm}\left[1,2(n) \cdot{ }^{3} \mathrm{H}\right]$ progesterone (sp. act. $55 \mathrm{Ci} / \mathrm{mol}$ ) were added to monitor progesterone recovery, and the samples were left in the cold overnight. The next morning, the samples were extracted with light petroleum ether and assayed for progesterone by radioimmunoassay as described earlier [14]

\section{Isolation of lipoproteins}

Human LDL (d 1.019-1.063 g/ml) and human HDL (d 1.063-1.215 g/ml) were isolated from sera of healthy donors by differential ultracentrifugation using $\mathrm{KBr}$ for density adjustments [17]. The lipoprotein fractions were subjected to washing in a low density and high density $\mathrm{KBr}$ solution as follows: The LDL fraction was layered under $\mathrm{NaCl}-\mathrm{KBr}$ solution of density $1.009 \mathrm{~g} / \mathrm{ml}$ and centrifuged at $45,000 \mathrm{rpm}$ overnight. The clear upper layer was removed and the lower $\mathrm{LDL}$ fraction was then layered over $\mathrm{NaCl}-\mathrm{KBr}$ solution of density $1.073 \mathrm{~g} / \mathrm{ml}$ and again centrifuged overnight. The clear lower layer and the contaminants were removed. The corresponding densities of $\mathrm{NaCl}-\mathrm{KBr}$ solution for purification of $\mathrm{HDL}$ were 1.053 and 1.225 , respectively. The isolated lipoproteins were dialyzed for $48 \mathrm{~h}$ against four changes of $0.15 \mathrm{M} \mathrm{NaCl}$ containing $0.3 \mathrm{mM}$ EDTA. Electrophorectic analysis in SDS acrylamide slab gels $(9 \%)$ revealed that $L D L$ contained Apoprotein $B$, with little Apo E, and HDL contained mainly Apo AI, AII, and some Apo C. Cholesterol in the lipoprotein fractions was assayed by the procedure of Zak [18] and protein by the procedure of Lowry et al. [19]. Cholesterol:protein ratios averaged $0.34: 1$ and 2.0:1 for IIDL and LDL, respectively.

\section{Statistical analysis}

Statistical comparisons of the results were made using Student's $t$-test.

\section{RESULTS}

The responsiveness of collagenase dispersed luteal cells to exogenously added stimuli for protesterone production is shown in Fig. 1 (A-D). Increasing doses of hCG from 0 to $100 \mathrm{ng} / \mathrm{ml}$ significantly stimulated progesterone production. As expected, hCG response was potentiated by exogenously added LDL and HDL. The stimulatory effect of the added lipoproteins was seen at all doses of hCG. Thus, under the conditions of our experiments, the exogenously added lipoproteins stimulated progesterone production in response to hCG (Panel A). Steroidogenesis by the luteal cells was also stimulated by cholera enterotoxin (Panel B) from a dose of $0.001-10 \mu \mathrm{g} / \mathrm{ml}$, and, this stimulation was potentiated by exogenously added LDL and HDL (Panel B). The inclusion of 8-Bromo-Cyclic-AMP in the incubation medium also stimulated progesterone production, and the cyclic AMP response was significantly stimulated by both lipoprotein fractions (Panel C). The responsiveness to $\mathrm{LDL}$ and $\mathrm{HDL}$ followed the same pattern in response to these three stimuli. Porcine prolactin (NIH-P-S-12) by itself 

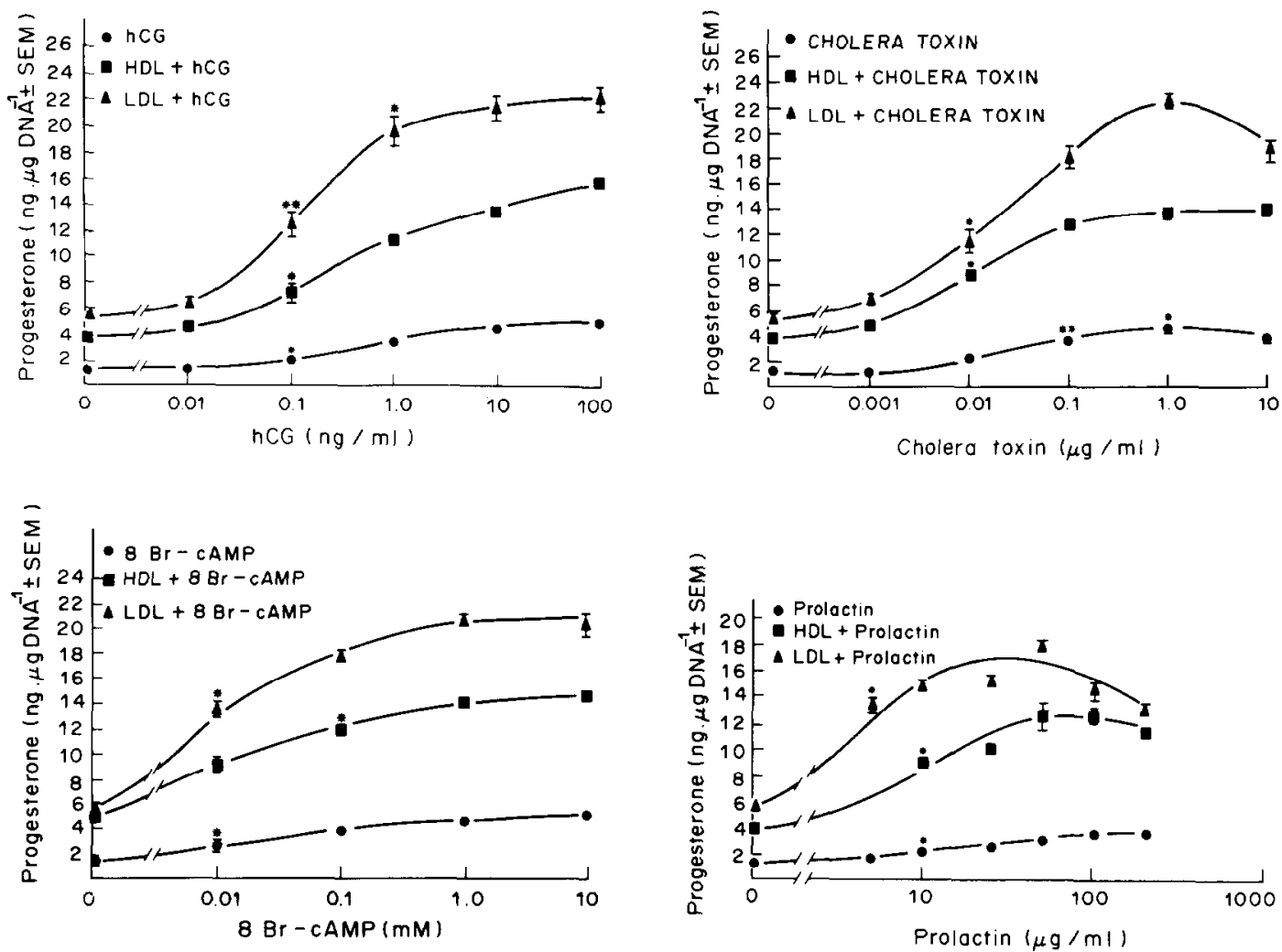

Fig. 1. Effect of the direct addition of hLDL or hHDL in vitro on progesterone production by rat luteal cells in response to increasing concentrations of hCG, cholera toxin, prolactin, and 8-Br-Cyclic-AMP. The luteal cells were isolated from luteinized ovaries ( 4 days post hCG) by collagenase trcatment. Aliquots of dispersed cells $\left(\sim 2 \times 10^{6}\right)$ were incubated with indicated concentrations of hCG (A), cholera toxin (B), Prolactin (D), and 8-Br-Cyclic-AMP (C), alone, and in the presence of hLDL or hHDL. After incubation at $37^{\circ} \mathrm{C}$ for $3 \mathrm{~h}$ in an atmosphere of $\mathrm{O}_{2}-\mathrm{CO}_{2}(95: 5, \mathrm{v} / \mathrm{v})$, the samples (cells and medium) were processed for progesterone determination by RIA. Each point represents the mean \pm SEM of quadruplicate determinations of triplicate incubations. Significances of difference (unpaired Student's $t$-test) between cells not exposed to exogenously added stimuli (concentration $=0$ ) and treated cells were: ${ }^{*} P<0.001$; ${ }^{* *} P<0.005$.

stimulated progesterone production at a concentration of $5 \mu \mathrm{g} / \mathrm{ml}$ and higher, and this response was significantly stimulated by both hLDL and hHDL, with maximum stimulation observed at $50 \mu \mathrm{g} / \mathrm{ml}$ prolactin (Panel D). The dose response relationship of prolaction on progesterone production followed a similar pattern as seen with the other stimulants for progesterone production in response to $300 \mu \mathrm{g} / \mathrm{ml}$ of $\mathrm{LDL}$ and $200 \mu \mathrm{g} / \mathrm{ml} \mathrm{HDL}$. Thus in the rat luteal cells, prolactin stimulated progesterone production, and this stimulation was potentiated when exogenous sources of cholesterol in the form of HDL and LDL were included in the incubation medium.

Responsiveness to $h C G$ and prolactin in the presence and absence of $H D L$ and $L D L$ during the life span of the corpus luteum

The responsiveness of the isolated luteal cell to exogenously added lipoprotein fractions in the presence of hCG or prolactin is presented in Fig. 2 (Panel A-D). The experimental protocol was identical in these experiments. The isolated cells were incubated alone or in the presence of $10 \mathrm{ng} / \mathrm{ml} \mathrm{hCG}$ or $50 \mu \mathrm{g} / \mathrm{ml}$ of prolactin. These doses were selected from the dose response curves presented in Fig. 1. Parallel incubations were also performed with cells in the presence of HDL $(500 \mu \mathrm{g})$ or LDL $(750 \mu \mathrm{g})$. In the third group of experiments, cells were incubated with hCG in the presence of HDL $(500 \mu \mathrm{g})$ or LDL $(750 \mu \mathrm{g})$. The cells were also incubated with prolactin $(50 \mu \mathrm{g} / \mathrm{ml})$ in the presence of hCG $(10 \mathrm{ng} / \mathrm{ml})$, and prolactin $(50 \mu \mathrm{g} / \mathrm{ml})$, in the presence of HDL $(500 \mu \mathrm{g})$ or LDL $(750 \mu \mathrm{g})$. These experiments were performed on different days of the life span of the corpus luteum.

On day 3 (Fig. 2, Panel A), hCG stimulated progesterone production about 2-fold. Addition of LDL $(750 \mu \mathrm{g})$ or HDL $(500 \mu \mathrm{g})$ alone stimulated progesterone production. Further addition of hCG in the presence of LDL or HDL potentiated this response. Prolactin alone caused significant stimulation of progesterone production over the control. Further addition of hCG to the incubation medium containing prolactin produced no further additive effect. Addition of LDL or HDL in the presence of pro- 

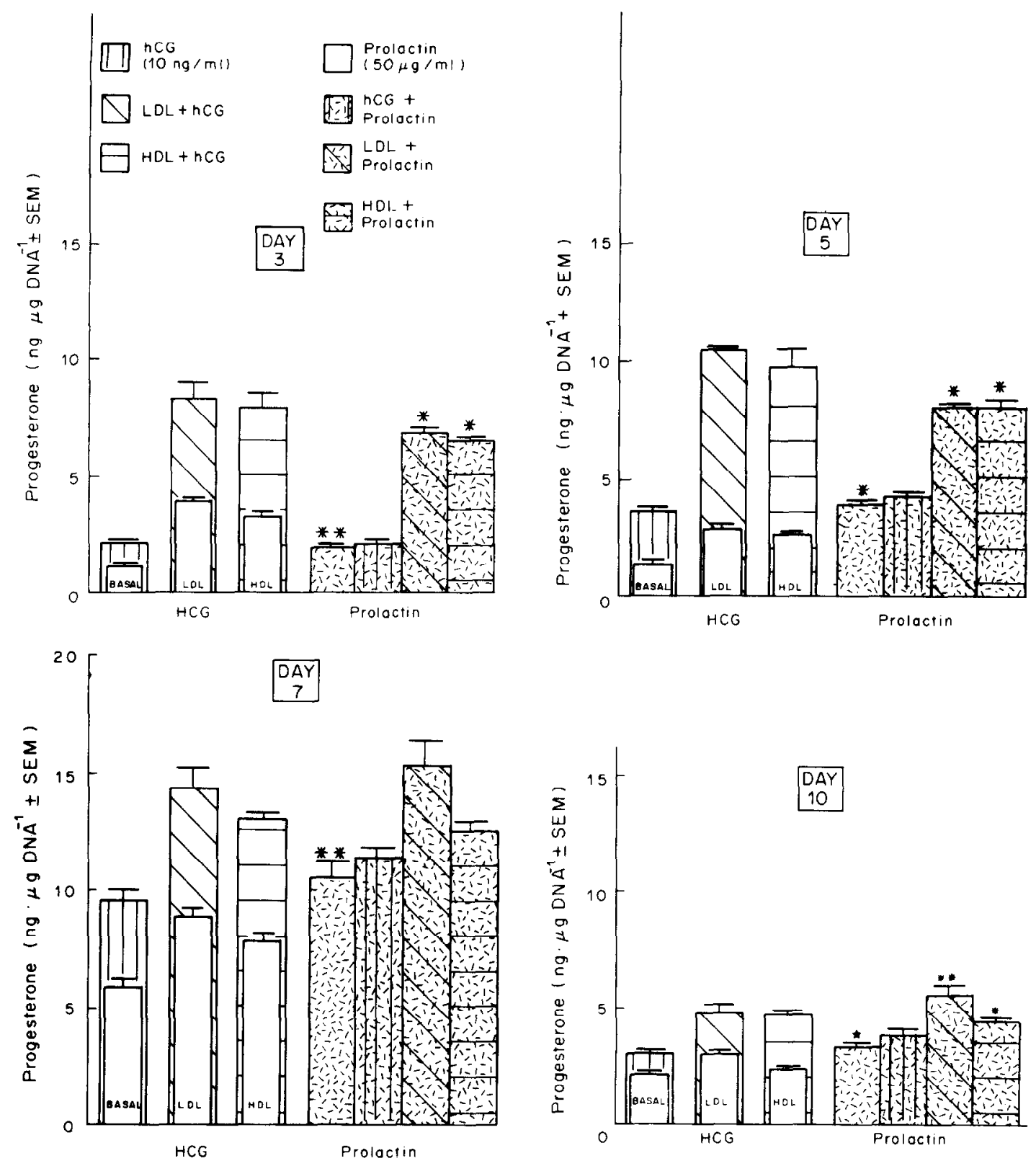

Fig. 2. Progesterone production by luteal cells at various stages of pseudopregnancy in response to hCG, prolactin, hLDL, and hHDL. Twenty-one-day old female rats were injected with 50 I.U. of PMSG followed $56 \mathrm{~h}$ later with $25 \mathrm{I}$.U. of hCG (day 0). On days $3(\mathrm{~A}), 5$ (B), 7 (C), and 10 (D) post hCG, rats were killed and luteal cells were isolated by collagenase treatment. Aliquots of dispersed cells $\left(\sim 2 \times 10^{6}\right)$ were incubated in a final volume of $0.4 \mathrm{ml}$ Medium 109 and indicated final concentrations of lipoproteins and hormones, either alone or in combination. Afler $3 \mathrm{~h}$ incubation in $\mathrm{O}_{2} / \mathrm{CO}_{2}(95: 5, \mathrm{v} / \mathrm{v})$ at $37^{\circ} \mathrm{C}$, the samples were assayed for progesterone by RIA. Values represent the mean \pm SEM of quadruplicate determinations of triplicate incubations. Significances of difference (unpaired Student's $t$-test) between basal and cells treated with prolactin alone were: $* P<0.001 ; * * P<0.005$. Significant differences between cells treated with prolactin alone and prolactin plus lipoproteins were: ${ }^{*} P<0.001 ;{ }^{* *} P<0.005$.

lactin further potentiated the prolactin response over 3-fold when compared with prolactin alone.

On day 5 (Panel B), the hCG response was almost 3-fold over basal production of progesterone. Addition of LDL and HDL potentiated this response. The effect of prolactin alone was more visible on day 5 than that seen on day 3 . Again, there was a minimum of potentiation of prolactin response by hCG. Addition of LDL or HDL further potentiated prolactin response.

On day 7 (Panel C), the steroidogenic response to both hCG and prolactin was at its maximum in terms of the amount of steroid produced, although the extent of stimulation was probably less than in 
previous days due to relatively high basal progesterone production. Total progesterone production in response to prolactin in the presence of LDL and HDL was comparable to that seen in the presence of hCG. Progesterone response to prolactin alone was also at its maximum on day 7. Again, there was no additive effect seen when $\mathrm{hCG}$ and prolactin were added together.

On day 10 (Panel D), responsiveness to hCG and potentiation by LDL and HDL were diminished. Likewise, prolactin response and its potentiation by exogenously added lipoprotein fractions were also considerably diminished.

On day 12 and day 14 the steroidogenic capability of luteal cells was its lowest level (data not shown). Neither hCG nor prolactin stimulated progesterone production to any significant extent, nor did the exogenously added lipoproteins have any effect.

\section{DISCUSSION}

The present studies demonstrate the responsiveness of a collagenase dispersed cell suspension prepared from luteinized rat ovaries during different stages of their life span to exogenous hCG and prolactin and the potentiation of this response by plasma lipoprotein fractions, LDL, and HDL. The steroidogenic response of luteal cells was also stimulated by exogenously added cholera enterotoxin and 8-Bromo-Cyclic-AMP, and this response was potenliated by LDL and HDL. Cholera enterotoxin is known to stimulate adenylate cyclase in a number of hormone responsive systems [21] including the ovary. Prolactin (NIH-P-S-12) also stimulated progesterone production at concentrations ranging from $5 \mu \mathrm{g} / \mathrm{ml}$ to $200 \mu \mathrm{g} / \mathrm{ml}$ in the absence of exngenous lipoproteins. It should be pointed out that prolactin response was not dramatic in the absence of exogenously added lipoproteins (Fig. 1, Panel D). However, in the presence of exogenously added LDL or HDL, the dose-response relationship of prolactin became highly obvious. For example, in the absence of exogenously added prolactin, but in the presence of LDL, progesterone production was $5.8 \mathrm{ng} / \mu \mathrm{g}$ DNA. In the presence of $5.0 \mu \mathrm{g}$ prolaction, the steroidogenesis was increased up to $13.3 \mathrm{ng} / \mu \mathrm{g}$ DNA. This difference would not have been apparent in the absence of exogenous cholesterol source. The prolactin preparation employed in this study had $\mathrm{LH}$ activity less than $0.005 \mathrm{NIH}-\mathrm{LH}-\mathrm{S}_{\mathrm{I}}$ units $/ \mathrm{mg}$. Thus, at $5 \mu \mathrm{g}$ of prolactin, the LH content would be less than 0.000025 units of NIH-LH-S, units. Such low activity would not be expected to stimulate progesterone production in our system. In addition, inclusion of prolactin up to $50 \mu \mathrm{g} / \mathrm{ml}$ in a radioreceptor assay specific for $\mathrm{LH} / \mathrm{hCG}$ type of activity produced no dose dependent inhibition suggesting that the prolactin preparation is free of $\mathrm{LH} / \mathrm{hCG}$ type activity. Thus, the effect of prolactin cannot be explained on the basis of contaminating LH activity.
However, electrophoresis of the prolactin preparation (NIH-P-S ${ }_{12}$ ) in 9\% SDS acrylamide gels (20) showed multiple bands upon staining with Coomassie blue. Thus, we cannot rule out the possibility that stimulation is not due to a previously unidentified stimulant other than $\mathrm{LH}$. The stimulatory role for prolactin on in vitro progesterone production, however, is compatible with previous reports that have suggested that rat corpora lutea are maintained by luteotropic factors other than LH [1-7]. The responsiveness of prolactin at a low dose was only apparent in the presence of exngennusly added sterol carriers, LDL and HDL.

Striking differences were also observed in the responsiveness of rat luteal cells to exogenous stimulants (Fig. 2, A-D). The basal steroid output was low on days 3 and 5 following hCG injection. Addition of hCG or prolactin stimulated progesterone production, and these responses were potentiated by the addition of exogenous HDL and LDL. On day 7, luteal cell steroidogenesis was at its maximum activity. Addition of lipoproteins in the presence of $\mathrm{hCG}$ and prolactin further stimulated this response. The basal hormone stimulated steroidogenesis in the presence and absence of exogenously added lipoprotein started to decline after day 7 . On day 12 and 14 the basal steroidogenesis was minimal and hCG, lipoproteins or prolactin had no stimulatory effect (data not shown). The fact that the dose response curve of prolactin is amplified in an incubation medium supplemented with LDL or HDL further underscores the importance of providing proper substrates when the steroidogenic potential of exogenous stimulants is tested. The mechanism of stimulation of steroidogenesis in response to prolactin is not understood at the present time. Since prolactin response was significant in the presence of exogenously added lipoproteins, this would suggest that prolactin may stimulate preferentially a step involved in the utilization of lipoprotein derived cholesterol in the rat ovary. In this context, it has been reported previously that prolactin stimulates the turnover of cholesterol esters in rat luteal cells [22]. Thus, prolactin might stimulate progesterone production in rat corpora lutea by stimulating the utilization of lipoprotein delivered cholesterol for progesterone production. Altcrnatively, prolactin might alter the metabolism of progesterone to $20 \alpha$-hydroxypregn-4-en-3-one since such a reaction is well documented in the ovarian tissue [23]. However, this possibility is unlikely since it will not explain the augmentation of prolactin response by exogenous lipoproteins.

Acknowledgements - This study was supported by NIH Grant HD 06656. We thank Ms Barbara Roderick for excellent secretarial services.

\section{REFERENCES}

1. Astwood E. B.: Ciba Foundation Colloquia on Endocrinology. Vol. V, Little, Brown, Boston (1968) p. 74. 
2. Evans H. M., Simpson M. E., Lyons W. R. and Turpeinen K.: Anterior pituitary hormones which favor the production of traumatic uterine placentomata. Endocrinology 28 (1941) 933-945.

3. Shelesnayk M. C.: Aspects of reproduction. Some experimental studies in the mechanism of ova implantation in the rat. Recent Prog. Horm. Res. 13 (1957) 269-322.

4. Akaka J., O'Laughlin-Phillips E., Antczak E. and Rothchild I.: The relation between age of corpus luteum (CL) and the luteolytic effect of an LH antiserum (LH-AS): Comparison of hysteroectomized pseudopregnant rats with intact pregnant rats for their response to LH-AS treatment at four stages of CL activity. Endocrinology 100 (1977) 1334-1340.

5. Lam P. C. O. and Rothchild I.: The influence of luteinizing hormone ( $\mathrm{LH}$ ), prolactin, and uterus on the development of a dependency on LH in the control of progesterone secretion in the pseudopregnant rat. Endocrinology 101 (1977) 1503-1516.

6. Garris D. R. and Rothchild I.: Temporal aspects of the involvement of the uterus and prolactin in the establishment of luteinizing hormone-dependent progesterone secretion in the rat. Endocrinology 107 (1980) $1112-1116$.

7. Hashimoto I., Asano T. and Wiest W. G.: Progestational function of perifused rat corpora lutea. Endocrinology 96 (1975) 421-430.

8. Schuler L. A., Scavo L., Kirsch T. M., Flickinger G. L. and Strauss J. F. III: Regulation of de novo biosynthesis of cholesterol and progestins, and formation of cholesteryl ester in rat corpus luteum by exogenous sterol. $J$. biol. Chem. 24 (1979) 8662-8668.

9. Azhar S. and Menon K. M. L.: Receptor-mediated gonadotropin action in the ovary: Rat luteal cells preferentially utilize and are acutely dependent upon the plasma lipoprotein-supplied sterols in gonadotropinstimulated steroid production. J. biol. Chem. 256 (1981) 6548.

10. Anderson J. M. and Dietschy J. M.: Relative importance of high and low density lipoproteins in the regulation of cholesterol synthesis in the adrenal, ovary, and testis of the rat. J. biol. Chem. 253 (1978) 9024-9032.

11. Brout B. C., Wiest W. G. and Collins D. G.: Effect of low density and high density lipoproteins on pro- gesterone secretion by dispersed corpora luteal cells for rats treated with aminopyrazolo-(3,4-d) pyrimidine. Endocrinology 110 (1982) 1572-1578.

12. Rajendran K. G., Hwang J. and Menon K. M. J. Binding, degradation, and utilization of plasma high density and low density lipoproteins for progesterone production in cultured rat luteal cells. Endocrinology 112 (1983) 1746

13. Parlow A. F.: A rapid bioassay method for $\mathrm{LH}$ and factors stimulating LH secretion. Fedn Proc. 17 (1958) 402.

14. Kawano A., Gunaga K. P. and Menon K. M. J.: Stimulatory effect of gonadotropins on the synthesis of adenosine 3,5'-cyclic monophosphate and progesterone production by suspensions of rat ovarian interstitial cells. Biochem. biophys. Acta 385 (1975) 88.

15. Clark M. R. and Menon K. M. J.: Regulation of ovarian steroidogenesis. Biochem. biophys. Acta 444 (1976) 23.

16. Burton K.: A study of the conditions and mechanism of the diphenylamine reaction for the colorimetric estimation of deoxyribonucleic acid. Biochem. J. 62 (1956) 315-232.

17. Havel R. J., Eder H. A. and Bragdan J. H.: The distribution and chemical composition of ultracentrifugally separated lipoproteins in human serum. $J$. clin. Invest. 34 (1955) 1345-1353.

18. Zak B.: Total and free cholesterol. Stand. Meth. Clin. Chem. 5 (1965) 79-89.

19. Lowry O. H., Rosebrough N. J., Farr A. L. and Randall R. J.: Protein measurement with the Folin phenol reagent. J. biol. Chem. 193 (1951) 265-275.

20. Fairbanks G., Steck T. L. and Wallach D. F. H.: Electrophoretic analysis of the major polypeptides of the human erythrocyte membranes. Biochem. 10 (1971) 2606-2616.

21. Finkelstein R. A.: Properties of cholera exo-enterotoxin (choleragen) and its natural toxoid (choleragenoid). Toxin 10 (1972) 441

22. Behrman H. R., Orczyk G. P., McDonald G. J. and Grep R. O.: Prolactin induction of enzymes controlling luteal cholesterol ester turnover. Endocrinology 87 (1970) 1251-1256.

23. Wiest W. G.: In vitro metabolism of progesterone and $20 \alpha$-hydroxy-pregn-4-en-3-one by tissues of the female rat. Endocrinology 73 (1963) 310-316. 